\title{
$\underline{\mathrm{L} \& \mathrm{~S}}$
}

Cadernos de Linguagem e

Sociedade

DOSSIEE: PERSPECTIVAS QUEER NOS ESTUDOS DA LINGUAGEM

\section{MATERIALIZAÇÃO DISCURSIVA DA CIS-HETERONORMATIVIDADE EM PERSPECTIVA ESCALAR: CONTRIBUIÇÕES PARA A LINGUÍSTICA QUEER}

\begin{abstract}
Discursive materialization of cis-heteronormativity in scalar perspective: contributions to Queer Linguistics
\end{abstract}

Materialización discursiva de la cis-heteronormatividad en perspectiva escalar: contribuciones a la Lingüistica Queer

Danillo da Conceição Pereira Silva ${ }^{1}$

Instituto Federal de Alagoas

Universidade Federal de Sergipe

Recebido em: novembro de 2020

Aceito em: dezembro de 2020

DOI: 10.26512/les.v21i2.35269

\footnotetext{
1 Professor de Língua Portuguesa do Instituto Federal de Alagoas (UFAL). Doutorando e Mestre em Estudos Linguísticos pela Universidade Federal de Sergipe (UFS). Especialista em Educação em Gênero e Direitos Humanos pela Universidade Federal da Bahia (UFBA). Pesquisador do Núcleo de Estudos em Discursos e Sociedade da Universidade Federal do Rio de Janeiro (NUDeS/UFRJ).
} 


\title{
RESUMO
}

Este artigo tem como objetivo apresentar uma proposta de interpretação não-dicotômica para o modo como normas macrossociais, notadamente a cis-heteronormatividade, estão atrelados a micronormatividades, construídas entre sujeitos, nas interações situadas de que participam. Para isso, articulando noções de materialização discursiva e de escala, destaco o caráter processual do trabalho pragmático e semiótico em jogo nos processos locais de naturalização da cis-heteronormatividade. A partir da análise de dados de interações online, gerados numa etnografia da escala, demonstro como os traços discursivos da cisnormatividade, conforme postulados por epistemologias transfeministas (binariedade, pré-discursividade e permanência), são perspectivados em constante friç̧ão com conteúdos ideológicos da heteronormatividade. Por fim, recorrendo a tensionamentos contemporâneos no campo das Teorias Queer brasileiras, reflito sobre políticas de afetação, de tradução e de deslocamento que podem inspirar novas imaginações à Linguística Queer no Brasil.

Palavras-chave: Materialização discursiva. Escala. Cis-heteronormatividade. Linguística Queer. Transfeminismos.

\begin{abstract}
This article aims to present a proposal for a non-dichotomous interpretation of the way in which macrosocial norms, notably cis-heteronormativity, are linked to micronormativities, built between subjects, in the situated interactions in which they participate. To this end, articulating notions of discursive materialization and scale, I highlight the procedural character of the pragmatic and semiotic work at play in the local processes of naturalization of cis-heteronormativity. From the analysis of data from online interactions, generated in an ethnography of the scale, I demonstrate how the discursive features of cisnormativity, as postulated by transfeminist epistemologies (binarity, pre-discursiveness and permanence), are seen in constant intersection with ideological contents of heteronormativity. Finally, using contemporary tensions in the Brazilian field of Queer Theories, I reflect on policies of affection, translation and displacement that can inspire new imaginations to Queer Linguistics practiced in Brazil.
\end{abstract}

Keywords: Discursive materialization. Scale. Cis-heteronormativity. Queer Linguistics. Transfeminisms.

\section{RESUMEN}

Este artículo tiene como objetivo presentar una propuesta de interpretación teórico-analítica de cómo los sistemas normativos macrosociales, en particular la cis-heteronormatividad, se vinculan a las micronormatividades, construidas entre sujetos, en las interacciones situadas en las que participan. Para ello, articulando nociones de materialización discursiva y escala, destaco el carácter procedimental del trabajo pragmático y semiótico en juego en los procesos locales de naturalización de la cisheteronormatividad. A partir del análisis de datos de interacciones online, generados en una etnografía de la escala, demuestro cómo los rasgos discursivos de la cisnormatividad, postulados por las epistemologías transfeministas (binaria, prediscursividad y permanencia), se ven en constante fricción con contenidos ideológicos de heteronormatividade. Finalmente, recurriendo a las tensiones contemporáneas en el campo de las Teorías Queer Brasileñas, reflexiono sobre políticas de afectación, traducción y desplazamiento que pueden inspirar nuevas imaginaciones a la Lingüistica Queer en Brasil.

Palabras clave: Materialización discursiva. Escala. Cis-heteronormatividad. Lingüística Queer. Transfeminismos.

\section{INTRODUÇÃO}

A (hetero)sexualidade [e a cisgeneridade], longe de surgir espontaneamente do corpo de cada recémnascido, deve se inscrever ou se reinstruir através de operações constantes de repetição e recitação de códigos (masculino e feminino) socialmente investidos como naturais (Paul Preciado). 
A passagem do já clássico Manifesto Contrassexual, do filósofo espanhol Paul Preciado, que eu escolhi para ser a epígrafe deste texto sintetiza de modo bastante particular um dos argumentos centrais disso que, desde os anos 90, no contexto estadunidense e europeu e, desde os anos 2000, no Brasil, temos chamado - não sem muitas disputas - de Teoria(s) Queer (doravante TQ). Nesse sentido, poderíamos imaginar, ainda com Preciado, que queer se refere a um coletivo de miradas críticas engajadas em desnaturalizar as lógicas que fazem com que certos códigos que regulam a vida social, os quais produzem sentidos de normalidade e anormalidade para formas de vida específicas, sejam tomados como ontológicos, verdadeiros, essenciais. Acredito que essa desnaturalização de normas sociais que produzem os modos possíveis de ser sujeito, especialmente em termos de gênero e de sexualidade, é a tônica política e epistemológica de uma analítica transviada, para usar a proposta de antropofagia linguística de Berenice Bento para o queer.

Em face da infinidade de códigos culturais e políticos nos quais precisamos nos inscrever reiteradamente para nos tornarmos tipos reconhecíveis de sujeitos, ou seja, para assumirmos formas disciplinares de estabilização desses códigos, as "identidades" (homem, mulher, gay, lésbica, branco, negro etc.), estão dois códigos de regulação bastante articulados e poderosos: a cisnormatividade e a heteronormatividade ou, em termos sintéticos, a cis-heteronormatividade. Segundo esse código de normalização, modos de vida, expectativas, moralidades, desejos, formas de usar o corpo, de expressar afetos, de viver (ou não) relações afetivas e reprodutivas são classificados em graus de normalidade e desvio, a partir de um modelo idealizado de heterossexualidade e de um modelo idealizado de cisgeneridade, este último pautado na relação de coerência compulsória entre sexo/gênero/desejo, para usar a expressão de Judith Butler (2017a).

Nessa direção, segue Preciado (2017, p. 27): “o sistema sexo/gênero é um sistema de escritura [...]" e "o corpo é um texto socialmente construído". Diante dessas metáforas sugestivas, me parece inevitável indagar: qual a relação entre linguagem e cis-heteronormatividade? É a essa pergunta, interseccionada com muitas outras, que a Linguística Queer tem buscado responder nos últimos trinta anos. Nas palavras de Rodrigo Borba (no prelo, p. 16), ela corresponde, grosso modo, ao "estudo das relações entre língua, gênero, sexualidade e as dinâmicas de manutenção e/ou contestação de normatividades (linguísticas e sociais)", assumindo um posicionamento político que leva à "desessencialização de identidades e desontologiza a língua, problematizando, assim, a relação supostamente sólida entre aquilo que falamos/escrevemos e aquilo que somos". Por isso, como eu disse em outro momento, xs linguistas queer estamos interssadxs justamente nos "efeitos performativos das multiplicidades de semioses e de engenharias linguísticas utilizadas por sujeitos, em suas interações cotidianas, a fim de produzir inteligibilidade sobre gênero, sexualidade e suas intersecções (raça e classe, por exemplo)" (SILVA, 2020a, p. 3). 
$\mathrm{Na}$ esteira desses problemas políticos de pesquisa, neste artigo busco apresentar uma proposta de interpretação para os modos como sistemas normativos macrossociais, especificamente a cis-heteronormatividade, estão atrelados a micronormatividades coconstruídas entre sujeitos nas interações localmente situadas de que participam. Para tanto, proponho a articulação entre uma noção já apresentada na Linguística Queer por Motschenbacher (2011), a de "materialização discursiva", com a perspectiva pragmática e semiótica dos processos de significação, praticada pela Antropologia Linguística, a partir da noção de "escala", como elaborada por Carr e Lampert (2016). Para além disso, faço dialogar tais construtos teórico-metodológicos com teorizações transfeministas de Viviane Vergueiro (2018) acerca da cisnormatividade e de seus traços discursivos de constituição, a saber: binariedade, pré-discursividade e permanência.

$\mathrm{O}$ argumento central proposto neste texto é que o modo como a cis-heteronormatividade, enquanto norma social de densidade regulatória macrossocial, se presentifica em interações situadas não é dado, ou mesmo totalizante, como pensam algumas teorizações sobre normalização social. Ao invés disso, acredito ser o labor pragmático e semiótico, mediante o caráter escalar dos processos de significação, o que promove a materialização discursiva da heteronormatividade e da cisnormatividade em interações situadas, bem como de suas intersecções. Com vistas a exemplificar a potencial produtividade do argumento proposto, analiso dados gerados a partir da interação entre Lilian e Felipe, na rede social Facebook, em torno da polêmica participação do empresário, ator e político brasileiro Thammy Miranda, um homem trans, num vídeo promocional de Dia dos Pais de uma empresa brasileira de cosméticos e perfumaria, a Natura.

O presente artigo é composto de três seções, além desta e das Considerações Finais. Na primeira seção, busco apresentar um panorama epistemológico não exaustivo da Linguística Queer, destacando premissas fundamentais para seus modos de conceber as relações entre linguagem e normatividades. Em seguida, na seção dois, apresento propriamente o argumento central deste trabalho, mediante a articulação das noções de materialização discursiva e de escala. Por fim, na terceira seção, exploro analiticamente os dados gerados a partir de interações online, com vistas a perspectivar a produtividade de uma noção escalar da materialização discursiva da cisheteronormatividade, informada por epistemologias transfeministas, para a Linguística Queer.

\section{UMA (BREVE) CARTOGRAFIA CRÍTICA PARA A LINGUÍSTICA QUEER}

Considerando bastante relevantes os vários esforços já engajados em narrar como questões de gênero e de sexualidade adentraram o foco de preocupações dos estudos linguísticos (OSTERMANN; FONTANA, 2010) e como uma parte desse campo passou a ser conhecida como 
Linguística Queer (BORBA, 2015; LEWIS, 2018; LÍVIA; HALL, 1997; SANTOS FILHO, 2020), doravante LQ, meu objetivo nesta seção não é propriamente (re)fazer um percurso histórico dessa abordagem. Em vez disso, buscarei focalizar alguns delineamentos epistemológicos decisivos para o projeto de uma crítica, linguística e semioticamente orientada, da cis-heteronormatividade e de seus atravessamentos interseccionais, dando, assim, o tom do percurso teórico-analítico que este trabalho pretende ilustrar.

Apesar das multiplicidades de posições e pontos de apego que têm guiado o trabalho de linguistas queer ao redor do mundo, e de uma gama de pesquisadorxs que pensam as relações entre linguagem, gênero e sexualidade informadxs por teorias queer, a meu ver, alguns liames têm sido compartilhados pela maioria delxs, quais sejam: a) uma concepção radicalmente performativa de linguagem, corpo, gênero e sexualidade; b) a afirmação da mediação semiótica nos processos de subjetivação e de inteligibilidade; c) o foco analítico nas práticas discursivas localmente situadas; d) a impureza como vetor teórico-metodológico. É sobre esses aspectos que discorreremos brevemente a seguir.

Talvez o mais particular dentre esses pontos seja a adoção de uma concepção radicalmente performativa de linguagem, corpo, gênero e sexualidade. Tal posição é notadamente tributária dos efeitos de desestabilização produzidos por uma visão de linguagem como forma de ação ${ }^{2}$ social, por isso regida por condições de realização em disputa com concepções que a encaram enquanto realidade autônoma, individual, apolítica, dotada de sentidos imanentes, estáveis e indiscriminadamente disponíveis a seus usuários. Nesses termos, uma visada performativa sobre a linguagem sublinha, grosso modo, que a ação linguística produz os sentidos - e, em última análise, isso a que nomeamos "realidade" - enquanto efeitos (e não causas) dessa mesma ação, contrariando, assim, crenças sobre a linguagem bastante naturalizadas na tradição do pensamento linguístico, a exemplo de narrativas sobre a linguagem (e sobre a língua) como um tipo de formalização racional de sistemas autônomos logicamente ordenados.

O impacto dessa posição, entre contínuas traduções e contágios políticos e epistemológicos ${ }^{3}$, chegou até os estudos feministas, inaugurando rupturas importantes para a constituição de posições pós-estruturalistas e queer nesse campo. Um exemplo pioneiro desse modo

\footnotetext{
${ }^{2} \mathrm{Na}$ esteira desse modo de ver a linguagem, podemos situar a revolucionária teoria dos atos de fala de John L. Austin (1990) e seus desdobramentos críticos na filosofia de Jacques Derrida (1991) e Judith Butler (1997), na antropologia de Bauman e Briggs (1990) e na linguística de Kanavillil Rajagopalan (2010). Para uma compreensão mais detalhada dessa trajetória, ver Danillo Silva (2019), Joana Plaza Pinto (2007) e Rodrigo Borba (2014).

${ }^{3} \mathrm{O}$ modo de apropriação do pensamento de Judith Butler sobre a linguagem para pensar gênero (e outros problemas filosóficos, éticos e políticos) é produzido na interseção entre diferentes epistemologias. Para além da influência da leitura desconstrucionista de Derrida sobre a teoria dos atos de fala de Austin, uma marca radical de seu trabalho é o intenso diálogo com a obra de Michel Foucault, especialmente no que tange a suas considerações sobre poder, discurso e norma.
} 
de apropriação da linguagem é a obra Problemas de Gênero: feminismo e subversão da identidade (2017a), publicado originalmente em 1990, de Judith Butler, a qual, se engajando no questionamento das fronteiras identitárias que constituíam o sujeito político do feminismo, "a mulher", alça o discurso à posição central das argumentações sobre corpo, sexo, gênero e desejo. Sua teorização rompe com uma visão dominante nos feminismos à época, segundo a qual o gênero seria uma "construção cultural" produzida sobre uma base biológica dada, o sexo, no interstício das relações entre sujeitos (homens ou mulheres) tomados como anteriores a essas próprias construções e relações.

As teorizações butlerianas desconfiam, então, por um lado, do sexo como um dado meramente biológico e, por isso, de partida, desentranhado de investimentos culturais (logo, de investimentos linguísticos), e, por outro, do apriorismo subjetivo e do binarismo da visão construcionista", segundo a qual "sujeitos" já estariam "lá", passivamente prontos para se "tornarem", pela ação institucional do poder opressor (tipificada em "papéis de gênero" bem delimitados, internalizados nos "processos de socialização"), homens OU mulheres. À revelia dessa posição, argumenta Butler (2017a, p. 56, grifos da autora):

[...] o gênero não é um substantivo, mas tampouco é um conjunto de atributos flutuantes, pois vimos que seu efeito é performativamente produzido e imposto pelas práticas regulatórias da coerência de gênero [...] O gênero é sempre um feito, ainda que não seja obra de um sujeito tido como preexistente à obra [...] Não há identidade de gênero por trás das expressões de gênero; essa identidade é performativamente construída, pelas próprias "expressões", tidas como seus resultados.

Em outras palavras, embora o gênero (e as identidades em geral) possa "carecer de carne ontológica", ou seja, do sentido aparente de uma interioridade estável e substantiva, esse efeito, de um gênero reconhecível, definível e, inclusive, nomeável, é “mantido vivo e visível através do grau contínuo de investimento que os indivíduos colocam em suas tarefas diárias” (MILANI, 2018, p. 5). Em uma perspectiva performativa, própria do queer, tanto os sujeitos quanto seus corpos, sexos, gêneros, sexualidades e desejos são encarados como efeitos materiais ${ }^{5}$ de determinadas práticas discursivas (fala, escrita, sinalização, linguagem imagética, entre outras) e de seu poder de realizar aquilo que enunciam ou, ainda, aquilo que parecem meramente descrever/nomear. Isso porque, nesses termos, não havendo possibilidade de exterioridade à cultura, também não há possibilidade de exterioridade à linguagem. Assim, a condição de possibilidade para que qualquer um desses atributos faça algum sentido na vida social ou, em outras palavras, para que possa projetar efeitos de

\footnotetext{
${ }^{4}$ Para uma crítica mais detida ao construcionismo feminista, ver Butler $(2017,2019)$.

${ }^{5}$ Sobre o problema da materialização para a TQ e para a LQ, argumentarei mais especificamente na seção seguinte.
} 
identidade e de diferença nas práticas sociais, é que eles sejam discursivamente constituídos. Em razão desses argumentos, a postura teórica, analítica e política da LQ está pautada na “desessencialização e [na] desontologização da relação entre linguagem e identidades sociais" (BORBA, 2015, p. 102).

A afirmação da constituição discursiva dos sentidos nas/para as práticas sociais, mediante o caráter performativo da linguagem, sublinha o fato de que o modo como determinados corpos e sujeitos poderão ser culturalmente significados em relação aos marcos normativos vigentes (de gênero e de sexualidade, por exemplo), o que Butler (2017a) vai chamar de "inteligibilidade", é sempre uma questão de mediação semiótica ${ }^{6}$. Assim, a inteligibilidade, processo básico das dinâmicas de poder implicadas na classificação e na hierarquização social e política das formas de vida, é efeito dos efeitos ideológicos do emprego de recursos semióticos situados. Disso depreendemos que inteligibilidade e processos de subjetivação são semioticamente produzidos. É nesse ponto que o trabalho de linguistas queer assume particular relevância, uma vez que passam, em geral, a dar atenção ao modo como indivíduos engajados em diferentes práticas discursivas são produzidos enquanto sujeitos reconhecíveis (inteligíveis) ao mobilizarem recursos semióticos de diferentes naturezas, a fim de reiterar ou transgredir normatividades sexuais e de gênero, por exemplo.

Ao contrário do que possa parecer numa leitura mais simplista do pressuposto levantado, não há axiomas gerais ou estabilidade na relação entre recursos semióticos e seus significados sociais. Diferentemente do que pensou a doutrina linguística saussureana acerca da relação significante/ significado no interior de um sistema idealizado falante/ouvinte ${ }^{7}$, a ligação entre recursos semióticos e significados sociais é indireta, mediada, sempre emergente, em última análise, indexical $^{8}$ (OCHS, 1992). Logo, recursos semióticos específicos, empregados localmente, apontam para sua trajetória de usos, mobilizando, assim, camadas de sentido mais sedimentadas na cultura, as quais são ressignificadas na dimensão situada e intersubjetiva das práticas discursivas.

\footnotetext{
${ }^{6}$ Em muitos momentos deste texto, opto por referências como "recursos semióticos" ou "semiótica", ao invés de propriamente "recursos linguísticos" ou "língua", com vistas a destacar uma elaboração corrente nos marcos socioculturais e antropológicos dos estudos da linguagem que se afasta do logocentrismo corrente na Linguística: o fato de que a língua (em seus diferentes recursos fonológicos, morfológicos, sintáticos, semânticos etc.) é encarada como um dos vários tipos de repertórios semióticos complexos, desigualmente distribuídos, a partir dos quais é possível performar significados sociais e efeitos de identidade na vida social, inclusive em termos de marcadores de gênero e sexualidade.

${ }^{7}$ Uma problematização interessante desse sistema pode ser encontrada em Fabrício (2017), especialmente por explicitar as ideologias linguísticas e os efeitos políticos subjacentes a esse modelo de comunicação e de produção de significados, o qual influenciou profundamente as teorizações e análises da Linguística desde a inauguração de seu mito fundador, a publicação do Cours de linguistique general, em 1916, de Ferdinand Saussure.

8 Para uma discussão mais abrangente sobre o modo como a noção de indexicalidade, vinda da Antropologia Linguística, tem sido incorporada na Linguística Queer, ver Rodrigo Borba, neste volume.
} 
Ou seja, a perspectiva indexical do significado sustenta que este emerge no interior das interações sociais, da negociação entre sujeitos engajados em práticas discursivas, sob o efeito de modelação advindo de vetores históricos, culturais, ideológicos, em jogo na própria produção dos significados ${ }^{9}$. Um bom exemplo disso são os resultados da pesquisa etnográfica de Borba e Osternann (2008) sobre os efeitos discursivos da manipulação do sistema de gênero gramatical por travestis. Grosso modo, xs autorxs concluíram que, apesar da reivindicação de uma identidade de gênero feminina pelas participantes da pesquisa e, em consequência, do uso corrente do sistema de gênero gramatical feminino para se autoreferirem, em momentos interacionais específicos elas reflexivamente agenciavam para si usos do masculino gramatical, o que, no contexto pesquisado, estava indexicalmente associado a significados convencionalmente atribuídos aos homens, numa cultura cis-heteropatriarcal como a brasileira, a exemplo de "coragem" e de "força".

$\mathrm{Na} L Q$, a atenção às relações indexicais que produzem os efeitos de sentido de recursos semióticos situados é chave central para a leitura da dimensão performativa da linguagem. Se o modo como a leitura butleriana da teoria da performatividade afirma a dimensão fabricada, via linguagem, de sujeitos generificados, sexualizados e do desejo, fica, para nós linguistas queer, uma pergunta intrigante e de importância particular para explanações críticas e empíricas satisfatórias: como? De que modo a performance - produção discursiva local realizada mediante o emprego de recursos semióticos situados - se conecta com a performatividade - sistema regulatório das performances enquanto adensamento histórico de performances repetidas? Como se explica a existência de performances subversivas em relação aos adensamentos históricos que regulam a ocorrência e a inteligibilidade dessas mesmas performances? Como performances insistentes podem alterar os termos solidificados de determinados códigos performativos?

É a desatenção para com essa mediação semiótico-discursiva entre performance e performatividade, estabelecida no jogo indexical, que conduz muitas análises queer a lugarescomuns de generalização e de naturalização de noções reificadas de "assimilação" e "resistência" em relação às normatividades sexuais e de gênero, ponto esse que retomarei adiante. Sob o influxo dessa crítica, chegamos a outro elemento de grande relevância para perspectivas queer nos estudos da linguagem, em geral, e para a LQ, em específico: o foco nas práticas discursivas situadas e a consequente construção de entendimentos a partir do que sujeitos fazem com a linguagem em suas práticas sociais cotidianas (desde as mais banalizadas àquelas mais institucionalizadas). Estas, por sua vez, são entendidas como práticas de intersubjetividade (BUCHOLTZ; HALL, 2005) nas quais os significados da vida social emergem, em detrimento de teorizações universalistas e modelos 
explicativos reificados baseados em axiomas herméticos. Esse ponto certamente produz tensionamentos importantes entre o posicionamento assumido por trabalhos correntes em TQ, inclusive naqueles praticados no Brasil, e as perspectivas radicalmente semiótica e sociocultural da fase atual da $L Q^{10}$.

Esse preterimento de uma analítica das normatividades sexuais e de gênero que parta necessariamente da observação crítica do modo como sujeitos de carne, osso e discurso vivem suas vidas tem conduzido progressivamente teorizações queer para um campo perigoso de abstrações. Um sintoma importante disso, conforme aponta Kira Hall (2013, p. 3), é a produção, por parte de muitxs teóricxs queer, de "uma compreensão da subjetividade que é de muitas maneiras incompatível com a investigação científica social". Em outras palavras, muitos pressupostos universalizantes produzidos pela TQ não se sustentam em face da análise de práticas discursivas situadas desenvolvidas pela LQ. Uma hipótese para essa constatação apresentada por Hall (2013) talvez seja uma crítica mais antiga lançada por linguistas preocupadxs com questões de gênero e sexualidade à TQ, a exemplo de Borba (2015): o paradoxo gerado por uma vertente de crítica social que emergiu de teorizações centradas em problemas de linguagem (filosofias pós-estruturalistas, por exemplo), aportada em departamentos de Retórica e Literatura Comparada, ter abandonado progressivamente a atenção à linguagem em sua trajetória.

Talvez uma boa ilustração das consequências dessas problemáticas apresentadas seja a assunção de noções apriorísticas, essencializadas ou "dadas" do que seja assimilação ou resistência às normas de gênero e de sexualidade (queer): casais gays compostos por homens cisgêneros monogâmicos seriam, desde já, exemplos dados da assimilação absoluta à heteronormatividade; já mulheres trans seriam, desde já, exemplos dados da transgressão absoluta à cisheteronormatividade. Ao invés disso, significados de assimilação ou de transgressão às normas de gênero e sexualidade são efeitos indexicalmente produzidos em performances locais, ou seja, negociados intersubjetivamente em processos emergentes da produção discursiva situada, mediante o agenciamento de diferentes recursos semióticos.

Por fim, nessa cartografia mínima de aspectos epistemológicos em geral validados entre os estudos linguísticos (aplicados) de orientação queer e a LQ, está a opção refletida pela impureza como vetor teórico-metodológico de pesquisa nesse campo. Se, por um lado, na LQ, a recusa à pureza disciplinar - tão característica da moderna Ciência Linguística e dos ideais de cientificidade

\footnotetext{
${ }^{10}$ No caso da LQ praticada no Brasil, tal atenção às práticas torna-se ainda mais vigorosa em razão dos caminhos que levaram à produção do próprio campo no país, o que se deu numa relação íntima com as perspectivas da Linguística Aplicada Indisciplinar (FABRÍCIO, 2017; MOITA LOPES, 2006). Esta, por sua vez, está pautada na investigação do modo como a linguagem integra a vida social em suas mais variadas dimensões, com atenção especial para questões identitárias, a exemplo de gênero, raça e sexualidade. Para uma discussão mais detida sobre a introdução da LQ no Brasil, ver Borba (2014, 2019, no prelo).
} 
e neutralidade pautados nos positivismos da Linguística hoje - advém do questionamento da ficção política da compartimentalização dos saberes; por outro lado, a impureza passa a ser uma prerrogativa também epistemológica em face de seus objetivos críticos. Sem sombra de dúvida, a complexidade de aspectos envolvidos nos fenômenos sociais sobre os quais a LQ se debruça, a exemplo de identidade, subjetividade, reflexividade, agência, gênero, corpo, desejo, práticas sexuais, somada às incontornáveis interseccionalidades de raça, de classe, de nacionalidade, de religião e afins, torna a indisciplina, a impureza e o trânsito condições para a realização da LQ.

Em termos práticos, como afirmei em outra ocasião (SILVA, 2020a), a LQ não se configura nem como uma subdisciplina da Linguística, nem mesmo da Linguística Aplicada, mas corresponde a uma orientação ético-política e teórico-metodológica em estudos da linguagem. Desse modo, aciona saberes de diferentes campos do conhecimento sobre gênero e sexualidades (em perspectiva antiessencialista ou queer), dispensando atenção particular ao modo como diferentes recursos linguísticos (fonéticos, morfológicos, sintáticos, semânticos, pragmáticos, discursivos, entre outros) e fenômenos semióticos (narrativas, intersubjetividade, escalas, multimodalidade, espacialidades, temporalidades, fala-em-interação, corporificação, afeto, contextualização, intertextualidade, letramentos, entre outros) participam da produção de performances situadas e de suas relações de reforço, fricção ou subversão em direção à cisheteronormatividade vigente. Uma consequência direta dessa característica é também a multiplicidade de metodologias para a geração de dados (pesquisa documental, etnografias, autoetnografias, etnografias online, cartografias, pesquisa-ação e afins) e de aportes teóricos que informem a análise de dados (análise da conversa, análise de narrativas, pragmática, análises do discurso, sociolinguística interacional, sociofonética, sociossemântica, linguística de corpus, estudos filológicos, paisagem linguística, antropologia linguística e afins).

Apesar desse caráter caleidoscópico da LQ, uma ressalva torna-se bastante importante neste ponto: nem todos os estudos linguísticos que se debruçam sobre questões de gênero e sexualidade partem de uma postura queer. O calibre ético-político dessa afirmação é mais importante do que o mero exercício de separatismo disciplinar que ele possa ensejar. Enquanto muitas abordagens subsumidas na perífrase "estudos de linguagem, gênero e sexualidade" se dedicam, grosso modo, a descrever regularidades e generalizações sobre usos linguísticos de indivíduos classificados a partir de etiquetas de gênero e sexualidade, tomadas enquanto categorias 
demográficas discretas de macronível ${ }^{11}$ (CAMERON, 2010), linguistas queer contemporâneos, por sua vez, estão geralmente engajados em problemas de pesquisa que lhes permitam desnaturalizar o aparente caráter essencial dos recursos linguísticos e daquilo que os sujeitos fazem com eles (performances), tensionando noções estáveis e universalistas de identidade. Assim, fica explícito que o alcance analítico da LQ não está restrito a produzir explicações sobre performances linguísticas e identitárias de sujeitos desviantes das normas de gênero, como se fosse essa uma "linguística LGBT". Em vez disso, justamente por assentar sua atenção nos efeitos das normatividades com as quais todos os sujeitos estão inexoravelmente implicados, possui potencial explanatório para dar conta de fenômenos linguísticos e semióticos que não necessariamente estão circunscritos aos acrônimos de políticas de identidade quaisquer que sejam (ver MOTSCHENBACHER, 2011).

\section{MATERIALIZAÇÃO DISCURSIVA COMO PROCESSO ESCALAR: A CIS-HETERONORMATIVIDADE}

Como grandes e poderosas narrativas sobre identidades, as quais circulam em diferentes tempos e espaços, comparecem em interações situadas? Como "formações discursivas" (FOUCAULT, 1969) altamente sedimentadas, a exemplo da heteronormatividade e da cisnormatividade, forjam corpos e subjetividades no interior de suas categorias de normalidade e desvio? No cerne dos problemas levantados por essas questões está o problema da relação entre normatividades sociais (enquanto realidades simbólicas, não-materiais) e processos de materialização dessas normas. Certamente, a questão da "matéria" como ponto de conflito no interior das teorizações feministas não é nada nova e já rendeu bastantes publicações, mas, a despeito disso, permanece uma questão atual, especialmente em face da proliferação de subjetividades políticas e de seus impactos nas práticas de ativismo e na pesquisa acadêmica. Dois

\footnotetext{
${ }^{11}$ Aqui cabe retomar o exemplo dos extensos trabalhos, em diferentes momentos da linguística, da linguística feminista e da sociolinguística variacionista, os quais operaram sob um paradigma expressionista de linguagem e identidade. Ou seja, os usos linguísticos dos membros de uma "comunidade de fala" (LABOV, 1972) eram explicados em função do lugar (tido como fixo e anterior à performance linguística) que tais membros ocupavam na estrutura social (mulheres falam assim porque são mulheres; homens falam assim porque são homens). Os usos linguísticos, em tese, expressariam as identidades. Nessa fase, eram comuns explanações sobre as especificidades linguísticas dos tipos sociais, a exemplo da "fala gay", reforçando então visões essencialistas sobre língua e sobre subjetividades. Um impacto importante que as teorias da performatividade linguística e que visões não essencialistas das identidades vão produzir sobre os estudos de "linguagem, gênero e sexualidade" é justamente a inversão do paradigma explicativo até então pautado na casualidade língua>identidade. Temos, assim, um paradigma performativo de linguagem $e$ identidade. Em outros termos, os efeitos de identidade produzidos e negociados contextualmente, no interior de "comunidades de prática" (ECKERT, 2010), são o resultado do emprego situado de determinados recursos linguísticos. Ainda que eu tenha escolhido colocar tais abordagens sob um eixo progressivo de temporalidade, vale dizer que há ainda uma larga produção de pesquisa linguística que segue fiel ao já contestado paradigma expressionista, com todas as implicações teóricas e políticas desse fato. Para uma visão mais detalhada dessa trajetória, ver também Ostermann e Fontana (2010).
} 
exemplos potentes dessas fricções acontecem no campo dos transfeminismos (ver BAGAGLI, 2016; FAVERO, 2020; VERGUEIRO, neste volume) e das perspectivas não-essencialistas sobre questões raciais (ver MELO; MOITA-LOPES, 2014; MUNIZ, 2016; SILVA, 2020b).

Em Corpos que importam: os limites discursivos do sexo, Butler (2019) oferece uma resposta às críticas sobre uma suposta ausência do corpo ou da "materialidade" na sua teoria da performatividade de gênero. Dentre outras coisas, ela argumenta que, diferentemente de visões construcionistas, sua teorização parte da "noção de matéria não como local ou superfície, mas como um processo de materialização que se estabiliza, ao longo do tempo, para produzir um efeito de demarcação, de fixidez, de superfície que chamamos de matéria” (BUTLER, 2019, p. 28). Em outras palavras, a "aparência de substância" ou "aparência de superfície" estável é, na verdade, efeito de um processo performativo que se desenrola sob um eixo temporal, uma historicidade. E mais: esse processo de materialização não é deliberado, mas regulado, a ponto de produzir "efeitos de demarcação", de identidade, poderíamos dizer.

No escopo das normatividades mais poderosas que regulam diferentes processos de materialização identitária está a cis-heteronormatividade, a qual corresponde a uma gama complexa de "estruturas, instituições, relações e ações que promovem e produzem a heterossexualidade [e a cisgeneridade] como natural, autoevidente, desejável, privilegiada e necessária" (CAMERON; KULICK, 2003, p. 55, acréscimo meu). Tal articulação normativa exerce "através de dispositivos de poder variados e interseccionalmente localizados, efeitos colonizatórios sobre corpos, existências, realidades vivenciadas, e identidades de gênero que, em diferentes graus e sentidos, não estão em conformidade com preceitos cistêmicos e normativos" (VERGUEIRO, 2018, p. 26). Assim, podemos dizer que a cis-heteronormatividade, bem como outros sistemas de regulação compulsória das identidades, tais como a branquitude, é um produto de uma "materialização discursiva" (MOTSCHENBACHER, 2011, p. 153) que afeta todas as formas de estabilização assignadas como identidades sexuais e de gênero, inclusive aquelas mais alinhadas às normas vigentes (cisgeneridade e heterossexualidade, por exemplo). Vale dizer que processos históricos de citação e recitação ${ }^{12}$ de normas hegemônicas atingem graus elevados de materialização discursiva exatamente quando alcançam efeitos de evidência, naturalidade e neutralidade.

Vale ressaltar que a noção de discurso em funcionamento nesse argumento é aquela derivada do pensamento foucaultiano, ou seja, discurso aqui corresponde a um conjunto de "práticas que formam sistematicamente os objetos de que falam” (FOUCAULT, 2012, p. 60) e não

\footnotetext{
${ }^{12}$ Nesse ponto, as noções derridianas de citabilidade e iterabilidade, parte importante de sua crítica aos performativos de Austin, são decisivas para as formulações sobre a performatividade do gênero de Butler. Para uma visão mais completa da trajetória dessa crítica, ver Silva (2019) e Borba (2014).
} 
propriamente a elaborações linguísticas em sentido estrito. Assim, recursos linguísticos e semióticos são uma dimensão imbricada da manifestação desse discurso e, por essa mesma razão, materializam sentidos normativos sobre gênero e sexualidade que ultrapassam as cenas de interação propriamente ditas, evidenciando, desse modo, os "complexos conjuntos de relações que existem entre as normas no 'macro-nível' [sic] social e as negociações mais locais dessas normas que ocorrem no 'nível micro"” (HALL; LEVON; MILANI, 2019, p. 484).

Assim, do ponto de vista das interações sociais, o modo como a materialização discursiva da cis-heteronormatividade se dá é sempre mediado, no sentido de que o poder que está em jogo nessas situações discursivas não reside nos atores sociais discretos, em si mesmos, ou nos conteúdos semânticos de itens linguísticos específicos, mas nos efeitos dos seus modos de agência semiótica (PARISH; HALL, no prelo) intersubjetivamente negociados. Isto é, segundo explica Motschenbacher (2018, p. 6), esses atores, por meio de suas performances locais, acionam indexicalmente "certos discursos normativos com vistas a normalizar ou deslegitimar certas práticas, desejos ou identidades sexuais [e de gênero]".

Nesse ponto, argumentamos, ainda, que o grau de materialização discursiva a que a cisheteronormatividade tenha chegado nas sociedades ocidentais seja inegável, dado o grau de naturalização e de institucionalização multiformes dela, e, desde um olhar centrado nas práticas discursivas locais de sujeitos concretos, esse processo de materialização discursiva não se realiza de modo unidimensional ou totalizante. Isso porque, conforme perspectivas pragmáticas e antropológicas das relações entre linguagem e sociedade, a exemplo da perspectiva escalar (CARR; LAMPERT, 2016), a produção dos significados na vida social - inclusive daqueles da ordem do gênero e da sexualidade - é sempre processual, laminada, coconstruída, uma vez que requer intenso trabalho discursivo de perspectivização por parte dos atores sociais engajados discursivamente.

Nesses termos, a materialização discursiva da cis-heteronormatividade não deveria ser encarada como um processo acachapante no qual normatividades macrossociais simplesmente extravasam, de forma direta, nas interações locais. Ao invés disso, as normatividades que emergem localmente são forjadas na prática discursiva mediante a produção de "hierarquias escaladas", ou seja, "efeitos dos esforços para classificar, agrupar e categorizar muitas coisas, pessoas e qualidades em termos de graus relativos de elevação ou centralidade” (CARR; LAMPERT, 2016, p. 3), os quais se ligam indexicalmente às macronormas, mais sedimentadas na cultura.

Em outras palavras, embora a relação do sujeito com as normas sociais, e aqui entendemos com as macronormas (cis-heteronormatividade, sexismo, brancocentrismo, capacitismo, por exemplo), seja inescapável, conforme sugere Butler (2017b), de um ponto de vista situado, pragmático e semiótico, "as escalas nas quais os atores sociais se baseiam para organizar, 
interpretar, orientar e agir em seus mundos não são dadas, mas são feitas - e bastante laboriosamente" (CARR; LAMPERT, 2016, p. 3). A relação entre os processos escalares e a materialização discursiva da cis-heteronormatividade é, a meu ver, bastante íntima, uma vez que processos semióticos engajados em classificar, perspectivizar, comparar, metaforizar sujeitos e situações discursivas informam, de partida, a existência de marcos normativos a partir dos quais esses processos são feitos. Ou seja, sistemas de valoração ideológica informam/e são informados por performances escalares, sendo estas mais ou menos naturalizadas de acordo com seu grau de materialização discursiva. Assim, conforme comentam Carr e Lampert (2016, p. 8), "o fato de a escala envolver pontos de vista e o posicionamento de atores a respeito a esses pontos de vista significa que não existem escalas ideologicamente neutras [...] as escalas que parecem mais naturais para nós são intensamente institucionalizadas".

Com vistas a ilustrar a produtividade analítica, para os objetivos da LQ, de se considerar a materialização discursiva da cis-heteronormatividade como um processo escalar, passo a discutir, então, dados gerados a partir de uma pesquisa que focaliza interações escritas online desencadeadas de forma viral na fanpage do ator, repórter e político brasileiro Thammy Miranda, na rede social Facebook. A postagem (FACEBOOK, 2020) que provocou tão intenso engajamento ${ }^{13}$ diz respeito a um vídeo publicitário, em celebração ao Dia dos Pais, produzido pela marca brasileira de cosméticos e perfumaria Natura, publicado em 09 de agosto de 2020. No vídeo, Thammy aparece ao lado de sua esposa, Andressa Ferreira, e do filho do casal, Bento, um bebê. O roteiro da peça publicitária se desenrolava em torno da importância de os pais "incentivarem seus filhos a seguirem seus passos com a liberdade de ser quem se é", assim o ator narrava especialmente suas experiências, medos e anseios em relação a Bento.

Apesar de a campanha ter sido celebrada por alguns segmentos sociais como um marco para a representatividade LGBT, uma vez que Thammy é um homem trans, a postagem viralizou e se tornou objeto de intensa midiatização e de embates discursivos nas redes sociais. Uma pesquisa realizada no buscador Google com os descritores THAMMY + MIRANDA + CAMPANHA + DA + NATURA produziu aproximadamente 79.700 resultados em 0,39 segundos ${ }^{14}$. Além disso, o assunto foi noticiado nos principais veículos de comunicação online do país, levando inclusive a empresa a dar uma declaração oficial sobre a repercussão da campanha ${ }^{15}$. Líderes fundamentalistas religiosos chegaram a convocar boicotes à Natura sob os argumentos de a campanha colocar "uma

\footnotetext{
${ }^{13}$ Quando da pesquisa, a postagem contava com 203 mil reações e 26 mil compartilhamentos.

14 Acesso em: 16 nov. 2020.

15 Disponível em: https://www.uol.com.br/ecoa/ultimas-noticias/2020/07/31/campanha-valoriza-pais-presentesthammy-e-um-diz-executiva-da-natura.htm. Acesso em: 16 nov. 2020.
} 
mulher para fazer o papel de um homem" e que isso seria "uma afronta aos valores cristãos"16. Foram também virais nas redes sociais vídeos de homens destruindo produtos da empresa como forma de protesto contra a participação de Thammy numa campanha de Dia dos Pais. Por fim, apesar das fakenews sobre um prejuízo financeiro que a campanha teria gerado à empresa, o fato é que as ações da Natura tiveram alta após a viralização da campanha ${ }^{17}$.

Apesar das diferentes trajetórias textuais (BLOMMAERT, 2010) assumidas por esse evento comunicativo, tendo em vista as limitações de um artigo, focalizarei, na seção que segue, algumas projeções escalares interacionalmente produzidas por sujeitos engajados na seção de comentários da própria postagem, que recebeu 203 mil reações e 23 mil compartilhamentos. Do ponto de vista metodológico, serei guiado pela proposta de Carr e Lampert (2016) acerca da "etnografia da escala", ou seja, um modo de produzir dados a partir da análise crítica do trabalho semiótico desempenhado por sujeitos, em situações de interação local, para perspectivizar seus mundos e forjar sentidos. Esse modo semiótico e situado de lidar com a linguagem desfaz, então, a clássica dicotomia micro-macro na análise de eventos sociais. De modo geral, as disputas discursivas travadas nos trabalhos semióticos investigados estavam centradas na projeção de escalas sobre a (i)legitimidade do gênero afirmado por Thammy e de sua decorrente (im)possibilidade de participar de uma campanha em homenagem ao Dia dos Pais, além de sua (im)possibilidade de ser "pai".

\section{Projetando escalas de nORMalidade E DESViO: PRÉ-Discursividade, BINARIEDAde E PERMANÊNCIA}

Os três elementos que compõem o subtítulo desta seção analítica dizem respeito àquilo a que a transfeminista Vergueiro (2018, p. 44) chama de traços discursivos da cisgeneridade, ou seja, pressupostos normativos têm funcionado para tornar identidades de gênero de pessoas cisgêneras como "naturais, normais, verdadeiras e ideais - com a consequente estigmatização, marginalização e desumanização de gêneros inconformes". Assim, pré-discursividade, binariedade e permanência constituem-se como eixos organizadores das equações de inteligibilidade, de classificação e de hierarquização de corpos e modos de vida, desde a assunção da coerência imaginada entre sexogênero-desejo (pênis-homem-heterossexual x vagina-mulher-heterossexual) ao status de norma universal, a cisnormatividade.

\footnotetext{
${ }^{16}$ Disponível em: https://www.metropoles.com/colunas-blogs/leo-dias/apos-processo-silas-malafaia-responde-thammye-artista-rebate-mais-amor. Acesso em: 16 nov. 2020.

${ }^{17}$ Disponível em: https://piaui.folha.uol.com.br/lupa/2020/07/29/verificamos-natura-milhoes-thammy/. Acesso em: 16 nov. 2020
} 
Como a própria descrição conceitual dessa operação crítica transfeminista nos permite perceber, o que entra em jogo, do ponto de vista semiótico, na produção situada da cisnormatividade são modos de perspectivizar os corpos e as subjetividades. Em outras palavras, a materialização discursiva da cisnormatividade envolve trabalhos semióticos escalares que, como afirmam Moita-Lopes e Fabrício (2018, p. 464, grifo meu), "separa, classifica, valoriza e classifica as coisas, as pessoas e seus atributos de acordo com parâmetros de normalidade e desvio". As análises escalares das sequências interacionais que seguem nos dão uma mostra disso.

\section{Figura 1 - Interação entre Lilian e Sérgio na seção de comentários ${ }^{18}$}

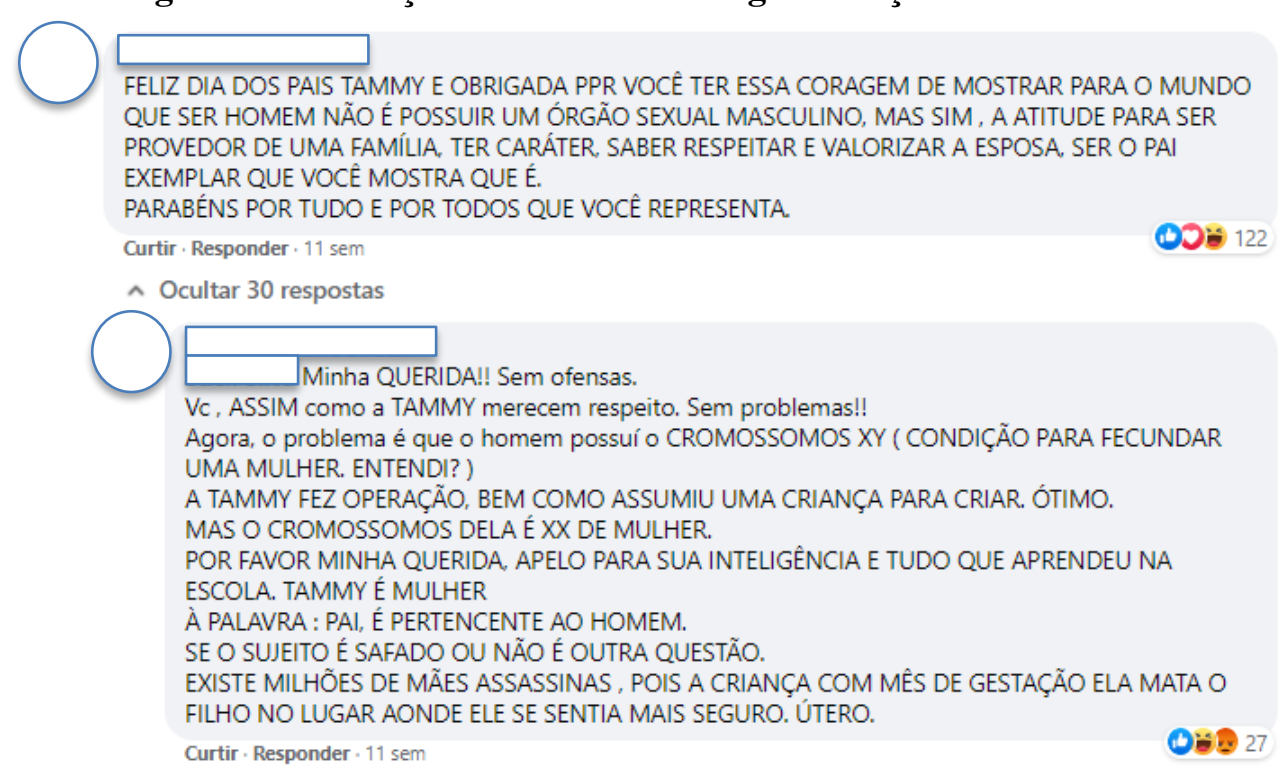

Fonte: Facebook (2020).

Em resposta ao vídeo comemorativo para o Dia dos Pais, lançado pela Natura na página de Thammy Miranda, conforme narrei na seção anterior, Lilian elabora um comentário que se pretende elogioso ao modo como Thammy vive sua paternidade, destacando a importância do seu exemplo de pai para o mundo, o que em nada teria a ver com configurações anatômicas, mas sim com o comportamento. O trabalho semiótico empregado por Lilian para construir seu modo de perspectivizar Thammy projeta uma gama complexa de escalas sobre "corpo", "autenticidade de gênero", "masculinidade" e "paternidade" que dão conta da relação de implicação entre a dimensão situada das práticas discursivas e a construção de normas situadas, com macronormas que possuem uma dimensão mais estável e ultrapassam os limites da interação em si.

\footnotetext{
${ }^{18}$ A fim de garantir o anonimato dxs comentadores, suas imagens e nomes forma retirados da captura de tela realizada. Os nomes atribuídos a elxs neste artigo são fictícios. Assim, o comentário inicial é atribuído a Lilian, já a réplica a ele a Felipe.
} 
De modo geral, Lilian se engaja no trabalho escalar por meio da construção discursiva de relações de "distinção" ou "disjunção" que funcionam no sentido de "classificar" (CARR; LAMPERT, 2016), em graus diferentes de autenticidade e legitimidade, performances de gênero, especialmente de masculinidade. Ao enunciar que "SER HOMEM NÃO É POSSUIR UM ÓRGÃO GENITAL MASCULINO”, a comentadora produz significados sobre o desatrelamento entre identidade social e configurações anatômicas (o sexo), afastando-se, assim, das narrativas do modelo biomédico de identidade (CAMARGO JR., 1997) segundo as quais ser homem ou mulher seria uma consequência direta da relação de presença/ausência de determinados caracteres sexuais dotados de significados imanentes a si mesmos. Assim, podemos dizer que, em alguma medida, a projeção escalar construída por Lilian parece, até aqui, desafiar o traço da pré-discursividade que forja a normatividade cisgênera.

Seguindo seu trabalho semiótico de distinção/classificação, após acionar uma escala que admite a condição de "homem" pela ausência de uma obrigatoriedade de configurações biológicas específicas, a comentadora passa a classificar elementos sociais supostamente atribuidores de autenticidade à referida identidade de gênero. Na sequência "PROVEDOR DE UMA FAMÍLIA", “TER CARÁTER”, "SABER RESPEITAR E VALORIZAR A ESPOSA”, ela se engaja na produção de uma escala que se organiza a partir de um novo marco normativo. Desta feita, o critério de gestão da legitimidade da identidade de gênero performada por Thammy, um homem trans, está atrelada a uma compulsória relação de citação à norma heterossexual, que metonimicamente se materializa no discurso de Lilian graças à invocação performativa de uma gama de traços atribuídos às performances de masculinidade, monogamia e paternidade, de acordo com as ordens discursivas da heteronormatividade. Conforme discute Motschenbacher (2018, p. $11)$,

[...] os ideais heteronormativos são normalmente associados a relacionamentos heterossexuais estáveis, monogâmicos, casamento, fidelidade vitalícia, descendência biológica conjunta, os homens como sendo superiores em termos de idade, força física, ocupação e renda, e as mulheres sendo (mais) responsáveis pela casa e pela educação dos filhos.

As projeções escalares que agem no comentário de Lilian nos permitem entrever os efeitos das relações de sobreposição e de constituição mútua entre diferentes sistemas normativos, a exemplo da cisgeneridade e da heteronormatividade. Além disso, apontam para a processualidade da materialização discursiva dessas normas nas interações locais e seu raio de regulação, inclusive em performances que poderiam ser tomadas aprioristicamente como completamente dissidentes (a exemplo de um homem trans que é pai). Eventos interacionais como esses chamam atenção para a 
complexidade (e até mesmo conflitividade) das escalas que entram em jogo na perspectivização de práticas sexuais, afetivas e reprodutivas macronormativamente hegemônicas (a exemplo da heterossexualidade e da monogamia reprodutiva) quando deslocadas de seu modo de inscrição macronormativamente preferível, a cisgeneridade. Em outras palavras, o trabalho semiótico em jogo no comentário de Lilian, que de partida se projetava enquanto legitimador e celebrativo da identidade de gênero de Thammy ("PARABÉNS POR TUDO E POR TODOS QUE VOCÊ REPRESENTA"), aponta para o caráter gradiente dos sistemas de inteligibilidade de gênero, o que tem a ver com o fato de que cisgeneridade e heterossexualidade "estruturam normativamente as maneiras de as pessoas perceberem e comunicarem sobre desejos, práticas e identidades sexuais [e de gênero]" (MOTSCHENBACHER, 2018, p. 11). A inteligibilidade da identidade de gênero performada por Thammy, segundo o trabalho escalar de Lilian, só parece possível dada a manutenção de algum grau de coerência com alguns dos elementos que compõem a relação de contiguidade sexo-gênero-desejo própria da matriz cis-heterossexual.

Em resposta ao comentário de Lilian, Felipe, após obedecer a estruturas rituais de interação que aparentemente poderiam denotar estratégias de polidez linguística (GOFFMAN, 2011; BROWN; LEVINSON, 1897) - “QUERIDA", "Sem ofensas" - inicia seu trabalho escalar por meio de uma sutil ação de disjunção/classificação que acaba por organizar, em termos de gênero, a esfera interacional em construção. De um mesmo lado, que na sua projeção estaria atribuído à ordem do "feminino", posiciona Lilian e Thammy, e se dirige a ela e a ele, num simulacro interacional de deferência e respeito próprios das estratégias de polidez empregadas por homens antes de uma sessão intensa de violência verbal, parte do que Deborah Cameron (2020) intitula como sexismo cotidiano, mas que opera como um tipo sutil de violência linguística de caráter transfóbico (SILVA, 2019). Essa disjunção inaugura o trabalho escalar de deslegitimação da identidade de gênero performada por Thammy.

Em seguida, o comentário de Felipe se engaja na produção de uma escala ancorada no traço da pré-discursividade como parte da fantasia performativa da cisgeneridade como natural, não-construída ou livre de investimentos culturais e discursivos. Ao enunciar "o homem possuí o CROMOSSOMOS XY (CONDIÇÃO PARA FECUNDAR A MULHER. ENETENDI?)”, o comentador passa a disputar o modo de escalar a autenticidade de gênero projetada por Lilian, que refutava a premissa regulatória da pré-discursividade. Se ela perspectivava o gênero como autêntico em detrimento da suposta coerência entre biologia e identidade (ainda que condicionando essa legitimidade a elementos da ordem heteronormativa), Felipe, por sua vez, valida em seu trabalho semiótico discursos médico-científicos normatizantes sobre gênero, sexualidade e reprodução para 
conferir sentido de autoridade a seu trabalho escalar, justamente por recorrer a uma escala bastante institucionalizada (CARR; LAMPERT, 2016), a escala da Saúde ${ }^{19}$.

O processo de materialização discursiva da cisnormatividade, projetada no trabalho escalar fabricado pelo comentário de Felipe, cita também discursos cristalizados sobre reprodução humana desde uma perspectiva heteronormativa e os atrela aos critérios de gênero inteligível (BUTLER, 2017a) que laboriosamente tece. Nesse sentido, ao apontar a suposta presença de "cromossomos $\mathrm{XY}$ " naqueles qualificados como "homens", segundo a ideologia normativa biomédica que orienta seu projeto escalar, o comentador estabelece como critério para participação nessa categoria a obrigatoriedade do atrelamento entre envolvimento afetivo, prática sexual e prática reprodutiva, outro sistema de linearidade normativa que sustenta a heteronormatividade.

Nesses termos, a condição para fecundar "uma mulher" (e aqui também há uma pressuposição normativa de que todas as mulheres sejam “fecundáveis"), e fecundá-la no interior de uma prática sexual que envolva necessariamente a reprodução de padrões, papéis e mecânicas corporais, fluídicas e políticas da heterossexualidade, torna-se critério para a aferição da legitimidade de gênero, para os modos de inscrição no gênero mesmo. E aqui vale ressaltar que nem todos os homens cisgêneros e heterossexuais (a exemplo daqueles que possuam algum impedimento físico ou psíquico para a prática reprodutiva nos termos normativos da cis-heteronormatividade) estão passíveis de serem lidos como "homens legítimos", segundo o horizonte normativo construído por Felipe. Nas palavras assertivas de Preciado (2020, p. 76), "a heterossexualidade se impôs como tecnologia social de reprodução politicamente assistida".

Em seguida, ainda escalando a legitimidade do gênero performado por Thammy nos termos da pré-discursividade, Felipe se engaja na sequência narrativa: "A TAMMY FEZ OPERAÇÃO, BEM COMO ASSUMIU UMA CRIANÇA PRA CRIAR. ÓTIMO. MAS OS CROMOSSOMOS DELA É XX DE MULHER". Para além da invocação do modelo biomédico de identidade, conforme já aludi, uma outra nuance do trabalho semiótico do comentador me chama atenção. Ao narrar uma sequência de eventos que dizem respeito às supostas ações de Thammy para afirmar seu gênero como homem, a exemplo da "mastectomia masculinizadora" e do exercício da

\footnotetext{
${ }^{19}$ Considerando que uma perspectiva escalar dos processos de materialização discursiva desfaz uma visão dicotômica entre esferas micro e macro dos processos interacionais e sociais, conforme discutido na seção anterior, a produção dos sentidos locais está invariavelmente ligada (indexicalmente) a dimensões culturais, históricas e ideológicas mais amplas. Retomo esse ponto neste momento da análise para ressaltar que a recorrente citação de discursos médicocientíficos para escalar as transexualidades de modo violento faz parte da gama de efeitos de longa duração da patologização das transexualidades, simbólica e materialmente produzida pela Medicina e pelos saberes psi (Psiquiatria, Psicologia e Psicanálise). Apesar da recente despatologização institucional das transexualidades por parte da Organização Mundial da Saúde (OMS), ocorrida apenas em 2018, e de iniciativas para alterar os discursos dos referidos campos do saber que até então hegemonicamente diagnosticaram o gênero, os efeitos simbólicos e discursivos da patologização permanecem discursivamente insistentes (ver BORBA; SILVA, 2020).
} 
paternidade (que é qualificada pelo comentador como menos do que ser "pai", como "ASSUMIR UMA CRIANÇA PRA CRIAR"), Felipe organiza tais acontecimentos num eixo temporal imaginado.

Ou seja, além de semioticamente reiterar a cisgeneridade como norma deslegitimadora da autenticidade do gênero reivindicado por Thammy - o que é indiciado inclusive pelo emprego do feminino gramatical (A TAMMY) -, não só cita o traço da pré-discursividade, como já discutido, mas também o da permanência. Nesse âmbito, Felipe projeta uma série de crenças acerca do que Vergueiro (2018) nomeia como o efeito de crenças cisnormativas sobre a imutabilidade e a estabilidade do gênero presentes na cisnormatividade. Nas palavras da autora, a permanência aponta para "uma certa coerência físiológica e psicológica em termos de seus pertencimentos a uma ou a outra categoria de 'sexo biológico' [...] de maneira consistente ao longo da vida de uma pessoa" (VERGUEIRO, 2018, p. 53), o que implica a premissa normativa da "permanência das identidades de gênero em suas relações e diálogos com suas formações corporais (p. 55). Tais crenças universalizantes materializam sobre corpos não cisgêneros "inevitabilidades e imutabilidades das fantasias cisnormativas sobre identidades de gênero e corporeidades" (p. 54).

Prosseguindo em seu trabalho semiótico, Felipe passa a projetar escalas de natureza diferentes das até aqui apontadas, mas ainda estabelecidas segundo os traços normativos da cisgeneridade. Ao qualificar os modos de perspectivar a identidade de gênero de Thammy empreendidos por Beatriz como alinhados, por analogia, à ignorância e à falta de escolarização, o comentador aciona discursos relativos ao saber acadêmico que, em seu projeto escalar, reforçariam aquelas do saber médico-científico já analisadas aqui. "APELO PARA SUA INTELIGÊNCIA E PARA TUDO O QUE APRENDEU NA ESCOLA”, enuncia ele. De modo interessante, tal forma de qualificar semioticamente um posicionamento que, em sua leitura, legitima a identidade de gênero de Thammy, parece informar, por derivação, o papel dos saberes acadêmicos e dos espaços formais de aprendizagem, a exemplo da escola, no sentido de produzirem modos de subjetivação de acordo com uma pedagogia da coerência de gênero, uma pedagogia da cis-heteronormatividade. Ironicamente, a escala projetada por Felipe parece reconhecer a falácia cisnormativa da prédiscursividade que ele tão laboriosamente produziu até aqui, uma vez que a verdade do gênero deveria ser ensinada na escola.

Por fim, recorrendo a um salto escalar bastante brusco e produtivo, o trabalho semiótico de Felipe fabrica uma analogia impensada entre a transexualidade e o aborto: "EXISTE MILHÕES DE MÃES ASSASSINAS, POIS A CRIANÇA COM UM MÊS DE GESTAÇÃO ELA MATA FILHO AONDE ELE SE SENTIA MAIS SEGURO. ÚTERO”. Tal analogia projeta escalas bastante institucionalizadas (CARR; LAMPERT, 2016) a exemplo do Estado enquanto responsável por 
garantir a proteção à vida dos fetos e por punir quem interrompa a gravidez, a quem Felipe qualifica como "MÃES ASSASSINAS". Por analogia, os efeitos de sentido projetados por essa escala que justapõe aborto e transexualidade são regimentados por ideologias cisnormativas que tomam a transexualidade, por um lado, enquanto desvirtuação, degeneração, mutilação do corpo e da pessoa, e, por outro, enquanto crime $^{20}$. Nessa trilha, cujos efeitos de sentido são maximizados por quantificações como "EXISTEM MILHÕES DE MÃES ASSASSINAS", tal como um aborto, os procedimentos para a afirmação de gênero (e os métodos de reprodução assistida) a que Thammy haveria recorrido são perspectivados enquanto um atentado à ordem natural, a um só tempo, do corpo, do gênero e das funções reprodutivas cis-heteronormativas. $\mathrm{O}$ trabalho escalar produzido por Felipe novamente indicia a interseção entre cisnormatividade e heteronormatividade na produção escalar do processo de materialização discursiva. Os empregos semióticos situados, ou as micronormas negociadas intersubjetivamente na interação, produzem seus significados ligando-se indexicalmente a macronormas sociais inscritas na cultura.

\section{CONSIDERAÇÕES FINAIS: POLÍTICAS DE AFETAÇÃO, TRADUÇÃO E DESLOCAMENTO PARA A LQ}

Torcendo os rituais clássicos de considerações finais dos textos acadêmicos, nesta seção não irei fazer exatamente um apanhado geral do recorrido ao longo do artigo. Ao invés de olhar para trás, para o "já feito", prefiro colocar em perspectiva o "daqui pra frente” como um exercício de imaginação política e epistemológica em LQ. Alguns caminhos produtivos para esse imaginar, especialmente pensando nas implicações da ampliação progressiva do interesse pelo campo em terras brasileiras, são, a meu ver: o da afetação, o da tradução e o do deslocamento como políticas. Explico-me.

Apesar da reconhecida, e historicamente justificável, ênfase no fato de as investigações em LQ se centrarem na heteronormatividade e em seus efeitos, desde uma mirada linguística e semioticamente orientada, é urgente que o campo avance no sentido de se deixar afetar por políticas epistemológicas emergentes dos campos queer da sociedade, de onde ela própria emergiu historicamente, evitando cair no mesmo encastelamento que vitimou a linguística tradicional. Isso quer dizer se deixar afetar pelas elaborações epistemológicas forjadas no interior dos movimentos sociais, desde perspectivas de mobilização política viadas, transfeministas, feministas negras, decoloniais, interseccionais, por exemplo. Vale dizer, enfrentando todos os tensionamentos certamente advindos da fricção entre diferentes marcos epistemológicos. Mas, se o queer é mesmo

\footnotetext{
${ }^{20}$ Dados semelhantes foram encontrados em pesquisa etnográfica prévia sobre a constituição da violência linguística de motivação transfóbica em comentários online no site de notícias brasileiro Gl (SILVA, 2020).
} 
um referente sem referência dada no mundo (BARRET, 2002), um significante em flutuação, não faz sentido circunscrevê-lo exclusivamente (e artificialmente) nos domínios da heteronormatividade. Digo artificialmente porque sabemos bem, pela teorização que já produzimos até aqui, sobre o caráter intrincado entre diferentes matrizes de poder que se retroalimentam e se informam mutuamente (heteronormatividade, cisnormatividade, branquitude, nacionalismo, classismo, capacitismo, ad infinitum).

Outro modo de caminhar que me parece bastante produtivo para imaginações em LQ, particularmente no Brasil, diz da urgência de traduzirmos as elaborações até aqui construídas em territórios outros, especificamente estadunidenses e europeus. Traduzir, aqui, não tem significado linguístico estrito, mas político e antropofágico. É sobre compreender que o funcionamento de matrizes de poder e inteligibilidade não pode ser transposto, ileso, através do Atlântico. As especificidades dos processos de dominação colonial, de racialização, de escravagismo comercial e de necrobiopolíticas à brasileira precisam entrar nessa política de tradução epistemológica e metalinguística. Não é sobre nenhum tipo de política de identidade teórica, ou purismo, ou nacionalismo acadêmico separatista. Ao contrário, é sobre retorcer as dinâmicas da geopolítica do conhecimento, em que, como sabemos, o Norte Global produz teoria, e nós, o Sul Global, as aplicamos passiva e pacificamente. E, se é assim, precisamos de políticas de contágio e de disseminação, assim como de trocas intelectuais em pé de igualdade política, numa agência contra toda forma de colonização epistêmica que nos negue o lugar de criação, autoria e teorização.

E, por fim, agora dialogando com o caminho teórico-analítico deste artigo, precisamos de uma LQ que possa deslocar os termos dos eixos organizadores das relações de produção do conhecimento naquilo que elas têm de mais prático: a fabricação de pesquisa é um bom exemplo. Precisamos pensar na força política de "nomear a normalidade" e "marcar o não marcado". A despeito de vastas pesquisas que nos contam os microdetalhes da performance linguística e semiótica de sujeitos dissidentes de gênero e de sexualidade, ainda há muito por saber sobre os processos semióticos de fabricação dos sujeitos posicionados no interior das ficções regulatórias que fundam o que é a dissidência, o queer. Se todas as identidades são inventadas por sistemas normativos e se isso acontece, segundo cremos na LQ, através de mediações semióticas multidimensionais, há muitas questões a serem postas. Algumas delas: por meio de quais processos interacionais e agenciamentos de signos pessoas se tornam, nas suas interações cotidianas, cisgêneras? E brancas? E heterossexuais? Como falam sobre monogamia? E sobre práticas sexuais e reprodutivas hegemônicas?

Uma possível estratégia para construir esses caminhos alternativos, ou essas imaginações para a LQ, pode estar no descolamento da atenção investigativa de uma busca excessiva para a 
emergência de rótulos identitários explícitos (gay, hétero, trans, homem, mulher), para um olhar mais detido nas práticas, nos agenciamentos semióticos em contexto que podem informar, de modo indireto, as performances relativas a gênero, sexualidade e raça, por exemplo. Esse foco nas práticas pode ser útil também para o enfrentamento à transposição de uma hegemonia da norma homossexual oculta na teoria queer para uma certa tradição da linguística queer estadunidense, conforme aponta Lewis (2018). Ou seja, em razão do seu foco excessivo na análise das homossexualidades, além de produzir invisibilidades sobre outras sexualidades não normativas, a exemplo da bissexualidade, "também invisibiliza outras performances identitárias de sexualidade e outras práticas sexuais” (LEWIS, 2018, p. 678).

No bojo dessas “outras performances", está também uma série de práticas que jogam de modo complexo, entre repetição e alteração, com os processos de materialização discursiva da cisheteronormatividade, a exemplo de construções discursivas sobre a vivência da heterossexualidade por pessoas não cisgêneras, bem como sobre a produção de significados sobre práticas reprodutivas que produzem fraturas nas relações de contiguidade entre sexo/gênero/desejo e entre conjugalidade/reprodução/parentalidade, a exemplo das aqui explicitadas. Precisamos, por fim, imaginar uma LQ no Brasil que, mediante políticas de afetação, tradução e deslocamento, se coloque, desde seu ponto de vista semiótico, a "problematizar as hierarquias de autenticidade e inteligibilidade entre corpos e identidades de gênero, através de uma proposição analítica e conceitual” (VERGUEIRO, 2018, p. 34).

\section{REFERÊNCIAS}

AUSTIN, J. L. Quando dizer é fazer. Porto Alegre: Artes Médicas, 1990.

BAGAGLI, B. P. A diferença trans no gênero para além da patologização. Periódicus, v. 1, n. 5, p. 87-100, 2016.

BARRETT, R. Is queer theory important for sociolinguistic theory? In: CAMPBEL-KIBLER, K.; PODESVA, R.; WONG, A. (ed.), Language and sexuality: contesting meaning in theory and practice. Stanford: CSLI Press, 2002. p. 25-43.

BAUMAN, R.; BRIGGS, C. Poetics and performance as critical perspectives on language and social life. In: COUPLAND, N.; JAWORSKI, A. (org.). The new sociolinguistics reader. New York: Palgrave Macmillian, 2010. p. 185-217.

BLOMMAERT, J. The sociolinguistics of globalization. Cambridge: Cambridge University Press, 2010.

BORBA, R. A linguagem importa? Sobre performance, performatividade e peregrinações conceituais. Cadernos Pagu, Campinas, n. 43, p. 441-474, 2014. 
BORBA, R. Falantes transviadxs: Linguística Queer e performatividades monstruosas. Cadernos de Linguagem \& Sociedade, v. 21, n. 2, neste volume.

BORBA, R. Linguística queer: algumas desorientações. In: BORBA, R. (org.). Discursos transviados: por uma linguística queer. São Paulo: Cortez, no prelo.

BORBA, R. Linguística queer: uma perspectiva pós-identitária para os estudos da linguagem. Entrelinhas, São Leopoldo, v. 9, n. 1, p. 91-107, jan./jun. 2015.

BORBA, R. $O$ (des)aprendizado de si: transexualidades, interação e cuidado em saúde. Rio de Janeiro: Fiocruz, 2016.

BORBA, R.; OSTERMANN, A. C. Gênero ilimitado: a construção discursiva da identidade travesti através da manipulação do sistema de gênero gramatical. Estudos Feministas, v. 16, n. 2, p. 409$432,2008$.

BORBA, R.; SILVA, D. C. P. Swings na scales of democracy: "transgender epidemic" and resistance of the (re)patologization of trans identities in contemporary Brazil. Trabalhos em Linguística Aplicada, no prelo. -

BORBA, R.; LAU, H. D. Conhecendo a Linguística Queer: Entrevista com Rodrigo Borba. Revista $X$, Curitiba, v. 14, n. 4, p. 8-19, 2019.

BROWN, P.; LEVINSON, S. Politeness: Some Universals in Language Usage. Cambridge: Cambridge University Press, 1987.

BUCHOLTZ, M.; HALL, K. Identity and Interaction: A Sociocultural Linguistic Approach. Discourse Studies, Thousand Oaks, v. 7, n. 4-5, p. 585-614, 2005.

BUTLER, J. Corpos que importam. Os limites discursivos do "sexo". São Paulo: n-1 Edições, 2019.

BUTLER, J. Excitable speech: a politics of the performative. London: Routledge, 1997.

BUTLER, J. Problemas de gênero: Feminismo e subversão da identidade. 13. ed. Rio de Janeiro: Civilização Brasileira, 2017a.

BUTLER, J. Relatar a si mesmo. Crítica da violência ética. São Paulo: Autêntica, 2017b.

CAMARGO JR., K. A biomedicina. Physis - Revista de Saúde Coletiva, v. 7, n. 1, p. 45-68, 1997.

CAMERON, D. Desempenhando identidade de gênero: conversa entre rapazes e construção da masculinidade heterossexual. In: OSTERMANN, A. C.; FONTANA, B. (org.). Linguagem, gênero, sexualidade. Clássicos traduzidos. São Paulo: Parábola, 2010. p. 129-150.

CAMERON, D.; KULICK, D. Language and Sexuality. Cambridge: Cambridge Press, 2003. 
CAMERON, D. Sexismo cotidiano. (2017). Tradução Rodrigo Borba. Blog Contxt. Publicado em 20 jun. 2020. Disponível em: http://contxt.letras.ufrj.br/item/12-sexismocotidiano.html. Acesso em: 10 out. 2020.

CARR, E. S.; LAMPERT, M. (org.). Scale. Discourse and Dimensions of Social Life. Oakland: University of California Press, 2016.

DERRIDA, J. Assinatura, acontecimento, contexto. In: DERRIDA, J. Margens da filosofia. Tradução de Joaquim Torres Costa, Antônio M. Magalhães. Campinas: Papirus, 1991. p. 349-373.

ECKERT, P. Linguistic variation as social practice. Oxford: Blackwell, 2000.

FABRÍCIO, B. F. Linguística aplicada e visão de linguagem: por uma INdisciplinaridade radical. Revista Brasileira de Linguística Aplicada, Belo Horizonte, v. 17, n. 4, p. 599-617, 2017.

FACEBOOK. Fanpage de Thammy Miranda. Postagem "Feliz dia dos Pais!!". Postado em 08 de agosto de 2020. Disponível em: https://www.facebook.com/283483845088486/videos/345654826837183. Acesso em: 10 set. 2020.

FAVERO, S. Cisgeneridades precárias: raça, gênero e sexualidade na contramão da política do relato. Bagoas - Estudos gays: gêneros e sexualidades, v. 13, n. 20, 19 jun. 2020.

FOUCAULT, M. A arqueologia do saber. 8. ed. São Paulo: Forense, 2012.

GOFFMAN, E. Ritual de interação: ensaios sobre o comportamento face a face. Petrópolis: Vozes, 2011.

HALL, K. "It's a hijra!": queer linguistics revisited. Discourse and Society, n. 24, n. 5, p. 634-642, 2013.

HALL, K.; LEVON, E.; MILANI, T. Navigating normativities: Gender and sexuality in text and talk. Language in Society, n. 48, v. 3, p. 481-489, 2019.

LABOV, W. Sociolinguistic Patterns. Philadelphia: University of Pennsylvania Press, 1972.

LEWIS, E. S. Do léxico gay à linguística queer: desestabilizando a norma homossexual oculta nas teorias queer. Revista de Estudos Linguísticos do Grupo de Estudos Linguísticos do Estado de São Paulo, n. 47, p. 675-690, 2018.

LÍVIA, A.; HALL, K. “É uma menina!”: a volta da performatividade à linguística. In:

OSTERMANN, A. C.; FONTANA, B. (org.). Linguagem, gênero, sexualidade. Clássicos traduzidos. São Paulo: Parábola, 2010. p. 109-129.

MELO, G. C. V.; MOITA-LOPES, L. P. A performance narrativa de uma blogueira: "tornando-se preta em um segundo nascimento". Alfa, São Paulo, v. 58, n. 3, p. 541-569, 2014.

MILANI, T. Queer performativity. In: HALL, K.; RUSTY, B. (ed.). The Oxford Handbook of Language and Sexuality, 2018. p. 1-17.

MISKOLCI, R. Teoria Queer: um aprendizado pelas diferenças. 2. ed. São Paulo: Autêntica, 2016. 
MOITA LOPES, L. P. (org.). Por uma Linguística Aplicada Indisciplinar. 1. ed. São Paulo: Parábola, 2006.

MOITA-LOPES, L. P.; FABRÍCIO, B. Does the Picture below show a heterosexual couple or not? Reflexivity, entextualization, scales and intersectionalities in a gay man's blog. Gender and Language, v. 12, p. 459-478, 2018.

MOTSCHENBACHER, H. Language and sexual normativity. In: HALL, K.; RUSTY, B. (ed.). The Oxford Handbook of Language and Sexuality, 2018. p. 1-23.

MOTSCHENBACHER, H. Taking queer linguistics further: sociolinguistics and critical heteronormativity research. International Journal of the Sociology of Language, n. 212, p. 149-179, 2011.

MUNIZ, K. Ainda sobre a possibilidade de uma linguística "crítica": performatividade, política e identificação racial no Brasil. DELTA, São Paulo, v. 23, n. 3, p. 767-786, 2016.

OCHS, E. Indexing gender. In: DURANTI, A.; GOODWIN, C. (ed.). Rethinking context: Language as an interactive phenomenon. Cambridge: Cambridge University Press, 1993. p. 335-358.

OSTERMANN, A. C.; FONTANA, B. (org.). Linguagem, gênero, sexualidade. São Paulo: Parábola, 2010. (Clássicos traduzidos).

PARISH, A.; HALL. K. Agency. In: STANLAW, J. N. (Ed). The International Encyclopedia of Linguistic Anthropology. John Wiley \& Sons, Inc, no prelo.

PINTO, J. P. Conexões teóricas entre performatividade, corpo e identidade. D.E.L.T.A, v. 23, n. 1, p. 1-26, 2007.

PRECIADO, P. Manifesto contrassexual. São Paulo: n-1 edições, 2017.

RAJAGOPALAN, K. Nova Pragmática: Fases e feições de um fazer. São Paulo: Parábola, 2010.

SANTOS FILHO, I. I. Linguística queer. Recife: Pipa, 2020.

SILVA, D. C. P. Performances de gênero e raça no ativismo digital de Geldés: interseccionalidade, posicionamentos interacionais e reflexividade. Rev. Bras. Linguíst. Apl., v. 20, n. 3, p. 407-442, 2020.

SILVA, D. C. P. Queer: o insulto, os movimentos e as linguísticas. Revista da ABRALIN, v. 19, n. 2, p. 1-5, jun. 2020.

SILVA, D. C. P. Sobre o caráter performativo da linguagem e a violência linguística. In: SILVA, D. C. P. Quando dizer é violentar: violência linguística e transfobia em comentários online. Salvador: Devires, 2019; p. 35-90.

SILVA, D. C. P. Quando dizer é violentar: violência linguística e transfobia em comentários online. Salvador: Devires, 2019. 
VERGUEIRO, V. Considerações transfeministas sobre linguagem, imaginação e decolonialidade: a identidade de gênero como categoria analítica. Cadernos de Linguagem \& Sociedade, v. 21, n. 2, neste volume.

VERGUEIRO, V. Sou travesti: estudando a cisgeneridade como uma possibilidade decolonial. Brasília: Padê, 2018. 